\title{
人性化理念在风景园林设计中的应用探究
}

\author{
李银芳 \\ 浙江刻意工程设计有限公司 \\ DOI:10.32629/as.v2i6.1693
}

[摘 要] 目前,城市中有非常多的风景园林建设项目,为现代人的生活增添了一抹亮色。人性化理念在园林设计当中占据着十分重要的地位,其 能够对风景园林的质量进行有效的评判, 这是风景园林设计发展的必要趋势。文中重点分析了人性化理念在风景园林设计中的应用, 希望对相关 工作者带来一定的参考价值。

[关键词] 人性化; 风景园林; 设计

随着我国社会经济的发展, 人们的生活质量和水平不断得到提高, 在满足物质文化需求的情况下, 对于居住环境有了更高的要求, 对风景 园林设计提出了新的要求。因此, 为了能够满足居民的生活需求, 风景园 林设计中应当注重人性化理念的应用, 有效改善居民的生活和居民环境, 满足人们个性化的心理需求, 进一步提升人们生活质量。在实际风景园 林设计中, 将人性化理念和风景园林设计有效融合, 保证风景园林设计 的高质量。

\section{1 人性化理念在风景园林设计中应用的作用}

1. 1 能够体现出城市的人文关怀

在园林景观设计中融入人性化理念, 可以通过物体的人性化表现实现 对人性化理念的传递, 进而更好的满足人们的心理需求, 提升人们的精神 舒适度, 这也是以人为本的一种体现, 将有形的园林景观通过无形的意境 进行有效的表达, 体现出城市的人文关怀。

1.2 有利于城市资源的整合和环境的改善

风景园林的设计不能完全遵从设计者的意愿随意的设计, 同时也不能 盲目的对其他成功设计的模仿, 更不能为了迎合领导的喜好而刻意的设计, 还需要融入人本理念。注重对城市资源的整合, 提升资源的利用率, 进而有 效的改善城市的环境, 使城市的园林景观不仅能够为人们提供精神上的放 松, 同时也能够为人们的生活提供一定的启示, 促进城市的现代化发展。

1.3 有利于突出城市的发展特色

从人性化的角度进行风景园林设计, 可以将人性化的理念充分的融入 到风景园林的设计中, 同时也为城市的发展特色提供研究的基础点, 体现 出城市发展的风格和特点, 进而赋予城市更具个性化的元素, 有利于城市 品牌的创立, 所以城市发展的特色和亮点也是可以通过风景园林景观进行 体现的。

时要挑选最为合适的区域, 能有效提高杨树的树势, 增强抗病虫性; 最后是 及时采伐, 及时的将已经枯死、或濒死边缘或被虫害侵蚀的杨树进行采伐 清除, 遗留下来的杨树要进行相应的防治处理。无论是从杨树的本身还是 其他方面的防治技术上, 都能对杨树做到有效的防治措施, 以促进杨树正 常正在发育。

\section{4 结束语}

林业的发展对生态环境建设有着重要作用, 对于东北区域的林业发展, 相关部门必须重视病虫害对林木危害的严重性, 树立正确的林木观念, 科 学合理的运用病虫害的防治技术, 积极开展病虫害的防治工作, 并从工作 中不断提高病虫害防治技术, 发现病虫害的规律特点并进行针对性的防治 措施, 达到最佳的防治效果, 提高东北地区的生态环境发展。

[参考文献]

\section{2 风景园林设计中人性化理念的应用原则}

2.1 细节性原则

风景园林在设计过程中会涉及到很多细节内容, 如园林内灯光的设计 以及防护装置的设计等, 都对风景园林整体的美观性和安全性有着重要意 义和影响。因此, 细节环节设计中融入人性化理念, 对风景园林整体的文化 特性以及人文关怀的体现有着推进作用。在实际设计过程中, 工作团队需 要先对风景园林的风格特点进行了解与掌握, 并对各个细节部分的设计要 点与原则进行深入研究, 从而为人性化理念的渗入奠定良好基础。

2. 2 协调性原则

协调性原则也是风景园林人性化设计中不可缺少的重要内容, 需要工 程团队能够注重人文与自然和协调发展, 这样才能进一步提高风景园林存 在的意义与价值。由于一些风景园林工程在设计过程中, 会出现过于迎合 人们生活需求现象, 导致园林自然环境不能真实的展现在人们眼前, 而是 被一些服务设施或者建筑物所替代。

\section{3 多元化原则}

风景园林设计是一项具有较高专业性和复杂性的工作体系, 其中涉及 到环境学、工程学以及美术学等多个专业学科, 若是在某个方面存在缺陷 将直接影响到风景园林设计的整体水平。因此, 在风景园林设计过程中, 设计人员不仅要确保其满足于城市功能的建设需求, 也要合理加强风景园 林的多元化设计。

\section{3 人性化理念在风景园林设计中的应用对策}

3. 1 注重对细节部分的设计

园林设计作品的细节充分展现了其整体的设计水准, 并且能够充分的 展现出人性化的理念。所以, 风景园林细节部分的设计在整个设计过程中 占据着十分重要的作用。在风景园林设计的过程中, 设计工作者以及施工

[1]黄万萍.林业栽培技术及病虫害防治管理措施的研究[J].农村实用 科技信息,2018(04):78-80.

[2]温勇.浅谈林业病虫害防治存在问题及生态防治技术 [J].农家参 谋,2018(08):97.

[3]胡心伟,赵玲. 基层林业管理与病虫害防治技术 [J].中国林业产 业,2017(02):3.

[4]杨萍.试论植树造林技术与森林病虫害防治研究[J].农村实用科技 信息,2017(8):47.

[5]郭建冰。林业栽培技术及病虫害防治措施分析 [J]. 花 卉,2019(6):245-246.

[6]刘莹.高职林业技术专业教学改革实践情况对比研究——以《森林 病虫害防治》课程为例[J].现代职业教育,2018(27):172-175. 
者需要高度的关注细节问题, 以人们的需求为基础, 充分的展现人性化设 计理念。比如, 在设计风景园林灯光的过程中, 应当保证灯光在照射的过程 中能够在园林任何路面上完全覆盖。对于灯光的光源, 需要选用黄色柔和 的光源, 需要充分的运用太阳能照明。在进行道路设计的过程中, 需要使观 赏者以最短距离达到自己想要去的地方, 并且在园林设计的过程中应当充 分的体现出 “曲径通幽处” 的幽深美感。而且, 还应当建设一些类似单双 杆的锻炼体育设施, 使人们在锻炼身体的过程中更加的方便。不仅能够使 人们体会到园林的美感, 还能够提升人们的体质。此外, 在设计风景园林时, 应当控制水池的深度, 需要采取恰当的保护方案, 人水交界地需要保证水 深位于二三十公分之间, 这样能够有效的避免安全事故的出现。再设计风 景园林时, 设计者需要注重细节, 使细节能够充分的满足人们的需求, 从而 有效体现人性化理念。

3. 2 能够满足人们的多样化需求

相关设计工作者不单单要重视风景园林设计的细节问题, 还需要在设 计的过程中重视人们各式各样的需求, 规划好每一个模块。现阶段人们的 需求多种多样, 传统单调的风景园林风格很难达到人们的要求标准。所以 设计工作者需要深入的了解风景园林设计的各项功能, 结合园林的布局展 开设计工作, 并且运用多样化的设计手段来开展设计工作。比如, 园林设计 过程中, 应当接近居民区, 不能建设在人流量过多的区域。在对成人活动以 及儿童活动进行规划的过程中, 应当有所区分, 必须远离危险区域以及人 行道。

\section{3 在设计的过程中体现人与自然和谐发展理念}

在风景园林设计的过程中应用人性化理念, 需要在设计规划的过程中, 充分的体现人与自然和谐发展的理念。这对风景园林设计工作者带来了极 大的挑战与高要求, 设计工作者在实际工作的过程中, 需要把握施工的整 体角度, 对风景园林设计和城市发展进程、社会进步等之间的联系深入的 分析。所以, 设计工作者在对风景园林进行设计规划的过程中, 需要保证建 筑物与景观的设计更为的协调。另外, 还需要确保园区当中各式各样的景 观可以与建筑物之间保持统一协调, 而且能够帮助园林建设良好的定位, 更加合理化与科学化的设计风景园林, 使其能够与人民群众的需求相符。 另外, 设计工作者需要站在人与自然和谐发展的层面上, 深入的分析研究 风景园林规划过程中的各项生态技能。包括生态农业技术、太阳能技术以 及建筑节能技术等。在对着一系列技术进行应用的过程中, 可以有效避免 园林建造过程为周边环境所带来的不利影响, 从而为风景园林的项目建设 融入到周边的自然环境当中创造有利的前提条件。

3. 4 注重人性化标识的设计

在风景园林的景观设计过程中, 人性化标识是一种不可或缺的元素,
能够有效的体现出风景园林设计中的各项细节。在多样化的设计当中, 很 多情况下正因为缺乏标志性的建筑, 致使出现了非常多的安全事故。比如, 如果园林当中存在动物园, 需要建造出 “动物伤人” 的标识, 而且还需要设 计出风格独特、有着提示意义的标识。如此一来, 不但可以增加风景园林 建设的美观度, 还可以引起游客对这些危险趋于的重视程度。此外, 在进行 标识设计的过程中, 需要保证标识具备美观性、委婉性的特征, 能够与园林 周围的环境相适应, 这样才能充分的体现出风景园林的创意性与趣味性。

3. 5 注重风景园林中的个性化设计

在设计风景园林的过程中, 需要充分的展现人性化的设计理念, 设计 工作者必须在有效的体现出个性化的设计要素。所谓个性化设计, 具体指 需要结合人文、文化、区域不同的需求, 设计出具备独特个性的风景园林。 事实上, 在设计风景园林的过程中, 往往很难受到局限性准则的制约, 主要 原因是因为在设计的过程中设计人员的不同以及组织的不同都具备自身 的设计模式。假如对设计准则进行制约, 就很难充分的展现出风景园林的 个性化设计, 也会使设计过程中个性化设计要素过少。虽然不会被设计准 则所制约, 但是在实际设计的过程中, 仍然需要在不同的层面上展现出各 个区域的不同风格。比如, 风景园林设计当中的建筑物所展现出的人文文 化等, 使其能够更上城市化发展的脚步。此外, 在风景园林设计的过程中, 需要仔细的排查设计方案, 综合全面的考量设计规划, 在园林地区地形差 异的基础上, 使园林景观的设计更加具备个性化的特质。另外, 设计工作者 在开展园林景观设计的过程中, 需要秉承着可持续发展的观念, 充分合理 的整合利用各项资源, 提升园林的经济收益。并且还需要对之后的维护保 养工作予以高度重视, 保证维护工作更加方便快捷, 这样才能充分的发挥 出风景园林的实效性。

\section{4 结语}

城市风景园林的设计是一项非常复杂和系统的工作, 其不仅要保证园 林设计的合理性和美观性, 同时也需要考虑到园林景观的人性化。所以在 风景园林景观的设计中, 必须要注重以人为本理念的体现, 进而使园林能 够满足人们多样化的需求, 真正的拉近人与自然、人与城市以及人与人之 间的距离, 进而保证风景园林景观效益的最大化。

[参考文献]

[1]曹丹.人性化理念在风景园林设计中的应用 [J]. 江西建 材,2017(22):64+63.

[2]隋刚德.试论人性化理念在风景园林设计中的应用 [J].农家参 谋,2018(17):90.

[3]万超. 人性化理念在风景园林设计中的应用研究 [J]. 居 舍,2018(21):129. 